\title{
Small airway dysfunction as predictor and marker for clinical response to biological therapy in severe eosinophilic asthma: a longitudinal observational study
}

Mustafa Abdo ${ }^{1 *} \mathbb{D}$, Henrik Watz ${ }^{2}$, Vera Veith' ${ }^{1}$, Anne-Marie Kirsten², Heike Biller ${ }^{1}$, Frauke Pedersen ${ }^{1,2}$, Erika von Mutius ${ }^{3}$, Matthias V. Kopp ${ }^{4}$, Gesine Hansen ${ }^{5}$, Benjamin Waschki1,6, Klaus F. Rabe ${ }^{1}$, Frederik Trinkmann ${ }^{7}$ and Thomas Bahmer ${ }^{1,8}$

\begin{abstract}
Background: Anti-T2 biological therapies have proven to effectively reduce acute exacerbations and daily doses of oral steroids in severe eosinophilic asthma. Despite the remarkable clinical efficacy, there are usually only moderate improvements in airflow limitation, suggesting that other measures of lung function like small airway dysfunction (SAD) might better reflect the clinical response. We aimed to investigate if measures of small airway function would predict and correlate with the clinical response to anti-T2 therapy.

Methods: We studied data of patients who were previously included in the German prospective longitudinal All Age Asthma Cohort (ALLIANCE) that recruits asthma patients of all severity grades and inflammatory phenotypes. The selection criteria for this analysis were adult patients with severe eosinophilic asthma under treatment with anti-T2 biological agents. Asthma control was assessed by asthma control test (ACT) and number of severe exacerbations. Small airway function was assessed by the frequency dependence of resistance (FDR, R5-20)) derived from impulse oscillometry (IOS) and the mean forced expiratory flow between 25 and $75 \%$ of the forced vital capacity $\left(\mathrm{FEF}_{25-75}\right)$. We also studied air trapping (RV and RV/TLC), blood eosinophils and FeNO. Patients were classified into responders and partial or non-responders. Clinical response was defined as at least 50\% reduction in annualized severe exacerbations and daily oral steroid doses accompanied with a minimum increase of 3 points in the ACT score. We used a Receiver Operator Characteristic (ROC) to study the capacity of FDR in predicting clinical response compared to other clinical variable like blood eosinophils. We studied the correlation between FDR measures and clinical response, represented by the ACT score and number of exacerbations, using linear regressions.
\end{abstract}

Results: 20 patients were included (mean age, $59 \pm 9$ years; $60 \%$ female; mean body mass index (BMI), $27.6 \pm 5.4 \mathrm{~kg} /$ $\mathrm{m}^{2}$; mean absolute blood eosinophils, $570 \pm 389 / \mu \mathrm{l}$; mean number of severe exacerbations 12 months prior to initiating the biological therapy, 5.0 \pm 3; mean predicted FEV1, $76 \pm 21 \%$; mean predicted FDR, $224 \pm 140 \%$; mean daily prednisolone dose, $6.4 \pm 4.9 \mathrm{mg}$; mean ACT score, $15 \pm 5$ ). Responders had significantly higher baseline FDR compared to partial or non-responders but similar FEV1, $\mathrm{FEF}_{25-75}$, RV and RV/TLC. ROC analysis showed that the

\footnotetext{
*Correspondence: m.abdo@lungenclinic.de

1 LungenClinic Grosshansdorf, Airway Research Center North

(ARCN), German Center for Lung Research (DZL), Wöhrendamm 80,

22927 Grosshansdorf, Germany

Full list of author information is available at the end of the article
}

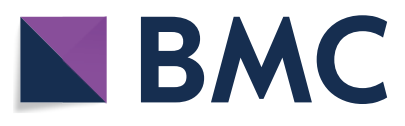

(c) The Author(s) 2020. Open Access This article is licensed under a Creative Commons Attribution 4.0 International License, which permits use, sharing, adaptation, distribution and reproduction in any medium or format, as long as you give appropriate credit to the original author(s) and the source, provide a link to the Creative Commons licence, and indicate if changes were made. The images or other third party material in this article are included in the article's Creative Commons licence, unless indicated otherwise in a credit line to the material. If material is not included in the article's Creative Commons licence and your intended use is not permitted by statutory regulation or exceeds the permitted use, you will need to obtain permission directly from the copyright holder. To view a copy of this licence, visit http://creativecommons.org/licenses/by/4.0/. The Creative Commons Public Domain Dedication waiver (http://creativeco mmons.org/publicdomain/zero/1.0/) applies to the data made available in this article, unless otherwise stated in a credit line to the data. 
combination of FDR and blood eosinophils had the best predictive capacity of the clinical response among all tested clinical markers (FeNO, FEV1, FDR, blood eosinophils) with an AUC of 85\% [67-100\%], $(\mathrm{Cl}=0.95, \mathrm{p}=0.01)$. Linear regressions indicated better associations between improvements in FDR and $A C T$ score $\left(R^{2}=0.42, p=0.001\right)$ than with FEV1 and ACT score $\left(R^{2}=0.25, P=0.013\right)$. Likewise, we observed better associations between improvements in FDR and reduction of exacerbations $\left(R^{2}=0.41, p=0.001\right)$ than with FEV1 $\left(R^{2}=0.20, p=0.025\right)$.

Conclusion: Our data suggest that severe SAD may represent a distinct phenotype of eosinophilic asthma that substantially improves under anti-T2 biological therapy. Measures of small airway function might be useful in selecting appropriate patients qualifying for anti-T2 biological therapy in addition to blood eosinophil count.

Keywords: Anti-T2 biologics, Asthma control, Small airways dysfunction, FEV1

\section{To the Editor,}

Anti-T2 biological therapy is recommended as an addon treatment for severe eosinophilic asthma [1]. Several randomized clinical trials have demonstrated the efficacy of anti-T2 therapy in reducing acute exacerbations and daily doses of oral steroids, while also indicating some improvements in forced expiratory volume in $1 \mathrm{~s}$ (FEV1) [2-4]. The improvements in FEV1 do not seem to correspond properly with the marked clinical response to biological therapy, suggesting that measures of large airway obstruction like the FEV1 might be a poor tool and that measures of other lung function abnormalities like small airway dysfunction (SAD) might better reflect the clinical response. Indeed, SAD is a hallmark of asthma that is associated with disease severity and poor symptom control [5]. Moreover, SAD is associated with frequent exacerbations $[6,7]$ and has a negative impact on daily physical activity [8]. We aimed to investigate if measures of SAD in patients with severe eosinophilic asthma might better correlate or even be helpful in predicting clinical response to biological therapy, thereby potentially describing a distinct phenotype within this severe asthma population.

In this study, we analyzed data of patients who were previously recruited in the prospective longitudinal All Age Asthma Cohort (ALLIANCE), a national cohort of pediatric and adult patients with asthma in Germany, initiated by the German Centre for Lung Research (DZL). The study was approved by the local ethics committee at the medical school Luebeck (Az.21-215) and is registered at clinicaltrials.gov (adult arm: NCT02419274) [9]. Since 2014, the adult arm of the ALLIANCE cohort recruits patients with mild to severe asthma and healthy controls. Patients had to be in specialist care for more than three months, and criteria of "difficult to control" asthma were addressed according to current guidelines [10]. Study visits take place in 12 months intervals. Patients had to have stable disease without acute exacerbations or respiratory tract infections within four weeks prior to study visits.
The selection criteria for this study were adult patients with severe eosinophilic asthma in whom a treatment with anti-T2 biological agent has been initiated while already being recruited into the observational ALLIANCE study and in whom at least one complete follow-up visit was available. Indication, prescription and administration of the biological therapy were not part of the study but rather were done by their respiratory physicians.

On each study visit, we assessed asthma control by asthma control test (ACT) as well as number of severe exacerbations 12 months prior to the study visit, defined as a burst of systemic corticosteroids for $\geq 3$ days [10]. We performed a spirometry, body plethysmography and impulse oscillometry (Masterscreen Body and IOS, Vyaire Medical, Germany) according to guidelines [11-13]. IOS is a feasible diagnostic tool that measures increased resistance in peripheral airways at tidal breathing, even in subjects with normal spirometry [14]. We studied the small airway function using both spirometry measures $\left(\mathrm{FEF}_{25-75}\right)$ and IOS measures (frequency dependence of resistance, FDR (R5Hz-R20Hz, $\mathrm{kPa} / \mathrm{l} / \mathrm{s})$ ). Percent predicted FDR values (FDR \%pred.) were calculated according to recently provided prediction equations by the German KORA cohort [15]. We also included measures of air trapping like the residual volume (RV) and RV to total lung capacity ratio (RV/TLC) as indirect markers for SAD. We studied peripheral blood eosinophils and fractional exhaled nitric oxide (FeNo) as surrogates for eosinophilic airway inflammation [16, 17]. Based on their clinical response, patients were classified into responders and partial-/non-responders: Responders $(n=13)$ had at least a $50 \%$ reduction of severe exacerbations averaged over the last 12 months or $\geq 50 \%$ reduction in oral steroid doses $[2,18]$ and additionally, an increase in the ACT score by at least 3 points as this is the minimal clinically important difference (MCID) [19]. Partial-/Non-responders had less than 50\% reduction in both severe exacerbations and in oral steroid doses and the ACT increase was beneath the MCID, or they even experienced worsening of symptoms (i.e. increase 
Table 1 Clinical characteristics of Responders and Partial-/Non-Responders at baseline and under treatment with Anti-T2 biological therapy

\begin{tabular}{|c|c|c|c|c|c|}
\hline Variable & Baseline & Under treatment & Mean of difference & $\begin{array}{l}\text { Percentage } \\
\text { change (\%) }\end{array}$ & P-Value \\
\hline \multicolumn{6}{|l|}{ Responders $(n=13)$} \\
\hline Age (years) & $59.4 \pm 9.8$ & & & & \\
\hline $\operatorname{Sex}(f / m)$ & $(9 / 4)$ & & & & \\
\hline $\mathrm{BMI}\left(\mathrm{kg} / \mathrm{m}^{2}\right)$ & $26.4 \pm 6.1$ & & & & \\
\hline Blood eosinophil count $(/ \mu \mathrm{L})$ & $620.8 \pm 378.8$ & $97.7 \pm 160.7$ & -523.1 & -84 & $<0.01$ \\
\hline $\mathrm{FEV}_{1}(\mathrm{I})$ & $2.1 \pm 0.88$ & $2.6 \pm 1.1$ & +0.520 & +24 & $<0.01$ \\
\hline FEV\% & $75.8 \pm 21.7 \%$ & $96.2 \pm 18.1 \%$ & $+20.4 \%$ & +26 & $<0.01$ \\
\hline $\mathrm{FEF}_{25-75}(\mathrm{l} / \mathrm{s})$ & $1.03 \pm 0.77$ & $1.64 \pm 1.06$ & +0.61 & +59 & $<0.01$ \\
\hline RV\% & $153 \pm 21 \%$ & $121 \pm 20 \%$ & $-32 \%$ & -21 & 0.02 \\
\hline $\mathrm{RV} / \mathrm{TLC}$ & $48 \pm 9 \%$ & $38 \pm 9 \%$ & $-10 \%$ & -21 & 0.02 \\
\hline $\mathrm{FDR}(\mathrm{KPa} / \mathrm{l} / \mathrm{s})$ & $0.26 \pm 0.20$ & $0.12 \pm 0.16$ & -0.13 & -50 & $<0.01$ \\
\hline FDR\%pred & $270 \% \pm 151$ & $168 \% \pm 85$ & $-103 \%$ & -37 & 0.02 \\
\hline FeNo(ppb) & $56.1 \pm 26.4$ & $40.8 \pm 27.5$ & -15.31 & -27 & $<0.01$ \\
\hline ACT score & $14.2 \pm 5.3$ & $19.8 \pm 4.7$ & +5.5 & +39 & $<0.01$ \\
\hline Number of exacerbations & $5.5 \pm 3.1$ & $1.1 \pm 1.2$ & -4.4 & -80 & $<0.01$ \\
\hline OSC dose (mg) & $5.9 \pm 5$ & $0.4 \pm 0.9$ & -5.5 & -93 & $<0.01$ \\
\hline \multicolumn{6}{|c|}{ Partial-/non-responders $(n=7)$} \\
\hline Age (years) & $60.86 \pm 8.30$ & & & & \\
\hline $\operatorname{Sex}(f / m)$ & $(3 / 4)$ & & & & \\
\hline $\mathrm{BMI}\left(\mathrm{kg} / \mathrm{m}^{2}\right)$ & $29.86 \pm 3.0$ & & & & \\
\hline Blood eosinophil count $(/ \mu \mathrm{L})$ & $474.3 \pm 420.1$ & $200.0 \pm 355.9$ & -274.2 & -58 & $>0.05$ \\
\hline $\mathrm{FEV}_{1}(\mathrm{I})$ & $2.0 \pm 0.58$ & $1.7 \pm 0.41$ & -0.343 & -17 & $>0.05$ \\
\hline FEV\% & $77.6 \pm 22.7 \%$ & $67.1 \pm 20.5 \%$ & $-10.4 \%$ & -13 & $>0.05$ \\
\hline $\mathrm{FEF}_{25-75}(\mathrm{I} / \mathrm{s})$ & $1.13 \pm 0.72$ & $0.81 \pm 0.45$ & -0.32 & -28 & $>0.05$ \\
\hline RV\% & $140 \pm 29 \%$ & $150 \pm 29 \%$ & $+10 \%$ & +7 & $>0.05$ \\
\hline $\mathrm{RV} / \mathrm{TLC}$ & $45 \pm 8 \%$ & $50 \pm 3 \%$ & $+5 \%$ & +11 & $>0.05$ \\
\hline $\mathrm{FDR}(\mathrm{KPa} / \mathrm{I} / \mathrm{s})$ & $0.13 \pm 0.11$ & $0.23 \pm 0.17$ & +0.10 & +76 & $>0.05$ \\
\hline FDR\%pred & $146 \% \pm 76 \%$ & $209 \% \pm 151 \%$ & $+63 \%$ & +43 & $>0.05$ \\
\hline FeNo (ppb) & $41.4 \pm 43.7$ & $57.9 \pm 38.7$ & +16.4 & +39 & $>0.05$ \\
\hline ACT score & $17.9 \pm 4.9$ & $17.3 \pm 3.6$ & -0.571 & -3 & $>0.05$ \\
\hline Number of exacerbations & $4.1 \pm 2.9$ & $3.0 \pm 2.0$ & -1.14 & -27 & $>0.05$ \\
\hline OSC dose (mg) & $7.2 \pm 5.1$ & $4.7 \pm 3.7$ & -2.6 & 36 & $>0.05$ \\
\hline
\end{tabular}

Values at baseline and under treatment, as well as means of differences ( + or -) are presented as means \pm standard deviations

Absolute blood eosinophils (cells/ $\mu \mathrm{l}$ ), FEV1: forced expiratory volume in the $1 \mathrm{~s}(\mathrm{I}), \mathrm{FEF}_{25-75}$ : forced expiratory flow between 25 and $75 \%$ of the forced vital capacity, RV: residual volume, TLC: total lung capacity, FDR (\%): frequency dependence resistance (R5-20 kPa/l/s) and predicted values, FeNO: fractional exhaled nitric oxide (ppb), ACT: asthma control test score, number of exacerbations in the last 12 months, OCS: oral corticosteroid (mg)

P values according to an appropriate test (t. test or Wilcoxon test). P-values in the last column represent test of baseline data vs. data under anti-T2 biological treatment within each of the two groups (responders vs. partial/non-responders). At baseline, clinical variables were also tested between groups and did not show any significant differences, except for FDR\%pred $(p=0.038)$

in severe exacerbations and a decrease in the ACT score) upon tapering systemic steroids. We evaluated the capacity of baseline FDR in predicting clinical treatment response by creating a Receiver Operator Characteristic (ROC). To evaluate FDR measures as potential markers for clinical response, we carried out comparative linear regressions between the change in FDR and other lung function measures with the change in severe exacerbations and in the ACT score.

Twenty patients with severe eosinophilic asthma under a treatment with anti-T2 agents (mepolizumab, $\mathrm{n}=18$; benralizumab, $\mathrm{n}=1$; dupilumab, $\mathrm{n}=1$ ) were included, (mean age, $59 \pm 9$ years; $60 \%$ female; mean body mass index (BMI), $\left.27.6 \pm 5.4 \mathrm{~kg} / \mathrm{m}^{2}\right)$. All patients were on inhaled corticosteroids (ICS; mean inhaled fluticasone 
Table 2 Area under the curve (AUC) of clinical predictors

\begin{tabular}{lllll}
\hline Clinical marker & AUC & P-value & \multicolumn{2}{c}{ 95\% Confidence Interval } \\
\cline { 4 - 6 } & & & Lower limit & Upper limit \\
\hline FDR\% & 0.79 & 0.03 & 0.59 & 0.99 \\
FeNO & 0.76 & 0.06 & 0.49 & 1.00 \\
Blood eosinophils & 0.64 & 0.31 & 0.36 & 0.93 \\
FEV1\% & 0.44 & 0.67 & 0.14 & 0.74 \\
$\begin{array}{l}\text { FeNO and blood eosino- } \\
\text { phils }\end{array}$ & 0.72 & 0.10 & 0.46 & 0.99 \\
$\begin{array}{l}\text { FEV1 and blood eosino- } \\
\quad \text { phils }\end{array}$ & 0.66 & 0.23 & 0.39 & 0.94 \\
$\begin{array}{l}\text { FDR and blood eosinophils } \\
\text { F }\end{array}$ & 0.85 & 0.01 & 0.67 & 1.00
\end{tabular}

Areas under the curves from (Fig. 1) used to compare the accuracy of each tested marker. P-Values and confidence intervals to define significant test $(p>0.05)$

equivalent $818 \pm 403 \mu \mathrm{g}$ ) and long-acting $\beta_{2}$ adrenoceptor agonists (LABA). 55\% were treated with long-acting muscarinic receptor antagonists (LAMAs) and $80 \%$ were on maintenance oral corticosteroids (OCS, mean daily prednisolone dose $6.4 \pm 4.9 \mathrm{mg}$ ) prior to starting with biological therapies. Mean predicted $\mathrm{FEV}_{1}$ at baseline was $76 \pm 21 \%$, mean $\mathrm{FEF}_{25-75} 1.1 \pm 0.73(\mathrm{l} / \mathrm{s})$, mean predicted RV $148 \pm 25 \%$, mean RV/TLC $47 \pm 8 \%$, mean FDR $0.21 \pm 0.18 \mathrm{kPa} / \mathrm{L} / \mathrm{s}$, mean FDR\%pred. $224 \% \pm 140 \%$, mean absolute blood eosinophils $570 \pm 389 / \mu \mathrm{l}$, mean FeNO $60 \pm 33$ ppb. Mean ACT score was $15.5 \pm 5.4$ points and patients experienced $5 \pm 3$ severe exacerbations 12 months prior to initiating the biological therapy. Between responders and partial-/non-responder, there were no significant differences in the baseline values of all clinical variables except for FDR\%pred, which was significantly higher in responders (Table 1). Area under the curve (AUC) for FDR\%pred. was better than for FeNO, blood eosinophils, and FEV1 (Table 2). At a cut off of $191 \%$ for FDR\%, we observed a sensitivity of $75 \%$, specificity of $71 \%$ and AUC of 79\% [59-99\%] (CI: 0.95, $\mathrm{p}=0.035$ ). The best AUC was achieved by combining FDR\%pred. with blood eosinophils count. At cut off values for FDR of 216\%pred, and blood eosinophils of 365/ $\mu \mathrm{L}$, the ROC curve showed a sensitivity of $75 \%$, specificity

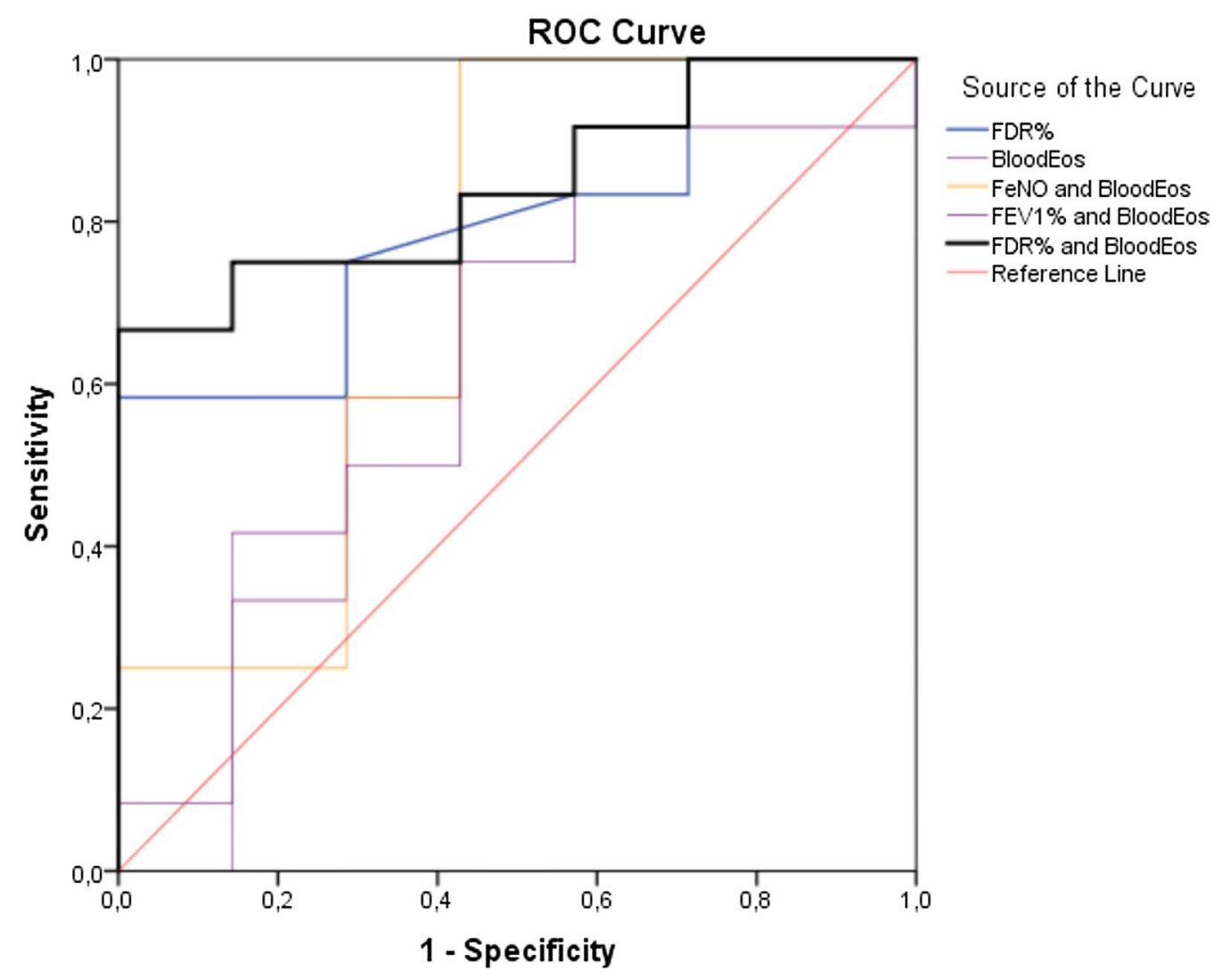

Fig. 1 Receiver Operator Characteristic (ROC) curve: $x$ axis (1-specifecity), $y$-axis sensitivity, each curve represents the predictability of each clinical marker (in different colors). AUC values and p-values for the separate variables are detailed in Table 2. A combination of FDR\%pred. with absolute blood eosinophil counts demonstrated the best predictive capacity ( $A \cup C=0.85$, p-value $=0.01, C 195=0.67-1.00$ ) 


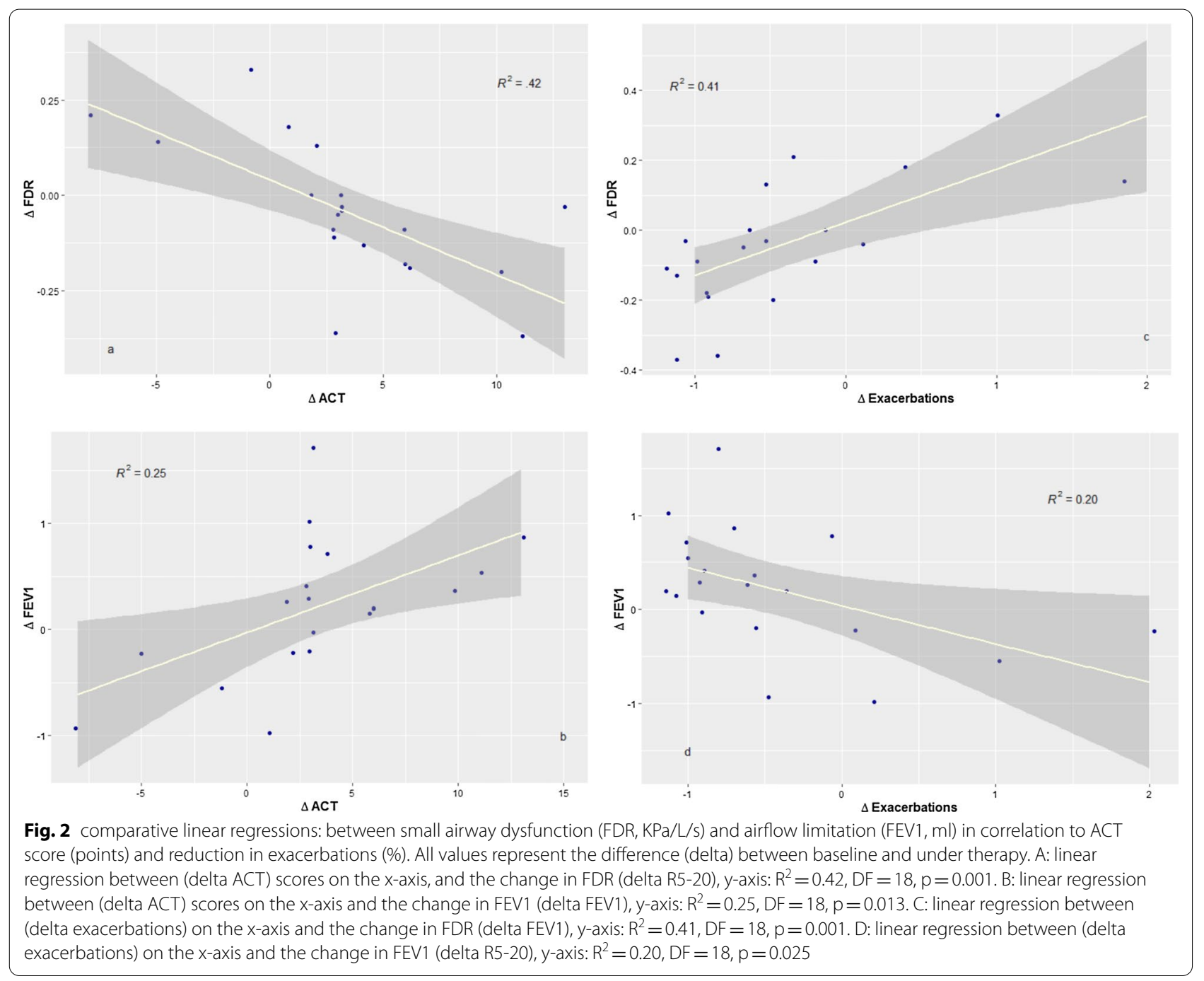

of $87 \%$, and AUC of $85 \%$ [67-100\%], $(\mathrm{CI}=0.95, \mathrm{p}=0.01)$ (Fig. 1).

Within response groups, responders to anti-T2 biological therapies experienced significant improvements in all clinical markers (i.e. lung function, inflammatory biomarkers) in contrast to partial/non-responders that did not demonstrate any statistically significant changes; details are given in (Table 1).

Linear regressions indicated better associations between improvements in FDR and ACT score than with FEV1 and ACT score as well as better associations between improvements in FDR and reduction of exacerbations than with FEV1 (Fig. 2). The other included lung function measures $\left(\mathrm{FEF}_{25-75}, \mathrm{RV}\right.$ and RV/TLC) were not superior to FEV1 when correlated to improvements in exacerbations or ACT with $\mathrm{R}^{2}$ values around 0.20 .
The main finding of our study is that SAD improves substantially under anti-T2 biological therapy in patients with severe eosinophilic asthma. Furthermore, pre-treatment IOS measures of SAD demonstrated to be meaningful predictors of clinical response, thereby indicating that severe SAD might describe a distinct phenotype with therapeutic implications among patients with severe eosinophilic asthma. Our results are consistent with the findings of previous studies which indicated that measures of SAD like $\mathrm{FEF}_{25-75}$, lung clearance index, regional ventilation inhomogeneity in acinar and conducting airways improve significantly under biological therapy $[20,21]$. Oscillometric measures of SAD seem to be feasible tools in selecting appropriate patients qualifying for anti-T2 biological therapy beyond the rather crude measurement of baseline blood eosinophils count that is frequently influenced by a multitude of factors, e.g. dose of inhaled or oral steroids [22], diurnal variations [23] 
and atopic comorbidities [24]. Our observations on the improvements in SAD might be explained by the findings that in severe asthmatics, small airway function is significantly altered with type-2 inflammation ( $\mathrm{T}$ cells and activated eosinophils infiltration) compared to large airways $[25,26]$. In our study, partial or non-responders experienced a $58 \%$ mean reduction of circulating blood eosinophils $(p>0.05)$, indicating the pharmacological effect of the biological therapy without marked improvements in clinical symptoms. These results are consistent with the finding of Kelly et al., which showed that despite the clear reduction in circulating and airway eosinophilia under mepolizumab, it does not suppress other eosinophil activation markers which might explain the clinical deterioration in some subjects [27].

The main limitations of this study are its observational nature and the small number of the included subjects. Further, additional measures of small airway function like inert gas distribution could have supported our findings. Therefore, clinical trials involving larger cohorts and multimodular assessment of small airway function are needed to confirm our observation. Finally, two patients had a treatment with either dupilumab or benralizumab which do not share the exact same pharmacological mechanism compared with mepolizumab.

Our data support that SAD is potentially linked to asthma control as SAD improves substantially under anti-T2 biological therapy in therapy responders. Measures of small airway function like the FDR might be useful in selecting appropriate patients qualifying for anti-T2 biological therapy in addition to blood eosinophil count and might also serve as markers to assess clinical treatment response in patients with newly initiated biological therapy.

\begin{abstract}
Abbreviations
ACT: Asthma control test; AUC: Area under the curve; BMI: Body mass index; DF: Degrees of freedom; FDR: Frequency dependence of resistance; FeNO: Fractional exhaled nitric oxide; FEV1: Forced expiratory volume in $1 \mathrm{~s}$; IOS: Impulse oscillometry; LABA: Long-acting $\beta_{2}$ adrenoceptor agonists; LAMA: Long-acting muscarinic receptor antagonists; MCID: Minimal clinically important difference; OCS: Oral corticosteroids; ROC: Receiver operator characteristic; RV: Residual volume; SAD: Small airways dysfunction; Th2:T helper 2 cells; TLC: Total lung capacity.
\end{abstract}

\section{Acknowledgments}

We thank Regine Wieland, Petra Hundack-Winter, Margret Gleiniger, Zaklina Hinz, Susann Prange, Corinna Derwort (LungClinic Grosshansdorf, Grosshansdorf, Germany) for their excellent support in study logistics.

\section{Authors' contributions}

The authors' contributions are as follows: Conception and design of the study: MA, FT, TB, HW; acquisition, analysis and interpretation: MA, VW, TB, FT, A-MK, $H W$; drafting the manuscript: MA, TB, HW, FT; critically revises the manuscript: TB, FT, HW, A-MK, HB, KFR, EvM, MVK and GH. All authors revised the manuscript for intellectual content and approved it for publication. All authors read and approved the final manuscript.

\section{Funding}

The ALLIANCE infrastructure is provided by the participating sites of the German Centre for Lung Research (DZL) and associated study centers and hospitals. Direct costs of the ALLIANCE Cohort are being paid by project grants from the German Federal Ministry of Education and Research (Bundesministerium für Bildung und Forschung, BMBF) as part of the DZL funding.

\section{Availability of data and materials}

The datasets used during the current study are available from the corresponding author on reasonable request.

\section{Ethics approval and consent to participate}

The study is a part from the prospective longitudinal All Age Asthma Cohort (ALLIANCE). The study was approved by local ethics committee at Medical School Luebeck, Germany, and is registered at clinicaltrials.gov (pediatric arm: NCT02496468; adult arm: NCT02419274).

\section{Consent for publication}

Not applicable.

\section{Competing interests}

MA reports no conflict of interest. HW reports personal fees and study honoraria of his employer from AstraZeneca, Boehringer Ingelheim, BerlinChemie, Chiesi, Novartis, GSK, and Sanofi outside the submitted work. WV reports no conflict of interest. AMK reports personal fees and study honoraria of her employer from AstraZeneca, Boehringer Ingelheim, BerlinChemie, Chiesi, Novartis, GSK, and Sanofi outside the submitted work. HB reports no conflict of interest. FP reports no conflict of interest. During the 36 months prior to publication, EvM Mutius reports to have received personal fees from Pharmaventures, from OM Pharma S. A., from Springer-Verlag GmbH, from Elsevier GmbH and Elsevier Ltd., from Peptinnovate Ltd., from Turun Yliopisto, from Tampereen Yliopisto, from Helsingin Yliopisto, from European Respiratory Society, from Deutsche Pharmazeutische Gesellschaft e. V., from Massachusetts Medical Society, from Chinese University of Hongkong, from European Commission, from Böhringer Ingelheim International $\mathrm{GmbH}$, from Universiteit Utrecht, Faculteit Diergeneeskunde, from Universität Salzburg, from Georg Thieme Verlag, from Japanese Society of Pediatric Allergy and Clinical Immunology (JSPACI), outside the submitted work; In addition, Dr. von Mutius has a patent LU101064-Barn dust extract for the prevention and treatment of diseases pending, a patent EP2361632: Specific environmental bacteria for the protection from and/or the treatment of allergic, chronic inflammatory and/or autoimmune disorders with royalties paid to Protectlmmun $\mathrm{GmbH}$, a patent Publication number EP 1411977: Composition containing bacterial antigens used for the prophylaxis and the treatment of allergic diseases, licensed to ProtectImmun GmbH, a patent Publication number EP1637147: Stable dust extract for allergy protection licensed to ProtectImmun $\mathrm{GmbH}$, and a patent Publication number EP 1964570: Pharmaceutical compound to protect against allergies and inflammatory diseases licensed to ProtectImmun $\mathrm{GmbH}$. MVK reports no conflict of interest. GH reports no conflict of interest. BW reports no conflict of interest. KFR reports personal fees from AstraZeneca, Boehringer Ingelheim, BerlinChemie, Chiesi, Novartis, GSK, and Sanofi outside the submitted work. FT received travel support from Actelion, Berlin Chemie, Boehringer Ingelheim, Chiesi, Novartis, Mundipharma and TEVA as well as speaker or consultation fees from AstraZeneca, Berlin Chemie, Boehringer Ingelheim, Bristol-Myers Squibb, Chiesi, GlaxoSmithKline, Novartis and Roche, Sanofi aventis, all outside the submitted work. TB reports personal fees from AstraZeneca, Boehringer Ingelheim, BerlinChemie, Chiesi, Novartis, GSK, and Sanofi outside the submitted work.

\section{Author details}

${ }^{1}$ LungenClinic Grosshansdorf, Airway Research Center North (ARCN), German Center for Lung Research (DZL), Wöhrendamm 80, 22927 Grosshansdorf, Germany. ${ }^{2}$ Pulmonary Research Institute At the LungenClinic Grosshansdorf, Airway Research Center North (ARCN), German Center for Lung Research (DZL), Grosshansdorf, Germany. ${ }^{3}$ Dr. Von Hauner Children's Hospital, Ludwig Maximilians University of Munich, Comprehensive Pneumology Center Munich (CPC-M), German Center for Lung Research (DZL), Munich, Germany. ${ }^{4}$ Division of Pediatric Pulmonology and Allergology, University Children's Hospital Luebeck, Airway Research Center North (ARCN), German Center for Lung Research (DZL), Luebeck, Germany. ${ }^{5}$ Department of Paediatric Pneumology, Allergology and Neonatology, Hannover Medical School, Biomedical 
Research in Endstage and Obstructive Lung Disease (BREATH), German Center for Lung Research (DZL), Hannover, Germany. ${ }^{6}$ Department of General and Interventional Cardiology, University Heart Center Hamburg, Hamburg, Germany. ${ }^{7}$ Department of Respiratory and Critical Care Medicine, Thoraxklinik, University of Heidelberg, Translational Lung Research Center Heidelberg (TLRC), German Center for Lung Research (DZL), Heidelberg, Germany. ${ }^{8}$ Dept for Internal Medicine I, University Hospital Schleswig-Holstein, Campus Kiel, Airway Research Center North (ARCN), German Center for Lung Research (DZL), Kiel, Germany.

Received: 29 June 2020 Accepted: 11 October 2020

Published online: 21 October 2020

\section{References}

1. Holguin F, Cardet JC, Chung KF, Diver S, Ferreira DS, Fitzpatrick A, et al. Management of severe asthma: a European Respiratory Society/American Thoracic Society guideline. Eur Respir J. 2020;55(1):1900588.

2. Rabe KF, Nair P, Brusselle G, Maspero JF, Castro M, Sher L, et al. Efficacy and safety of dupilumab in glucocorticoid-dependent severe asthma. N Engl J Med. 2018;378(26):2475-85.

3. Ortega HG, Liu MC, Pavord ID, Brusselle GG, FitzGerald JM, Chetta A, et al. Mepolizumab treatment in patients with severe eosinophilic asthma. N Engl J Med. 2014;371(13):1198-207.

4. Nair P, Wenzel S, Rabe KF, Bourdin A, Lugogo NL, Kuna P, et al. Oral Glucocorticoid-sparing effect of benralizumab in severe asthma. N Engl J Med. 2017;376(25):2448-58.

5. Postma DS, Brightling C, Baldi S, van den Berge M, Fabbri LM, Gagnatelli $A$, et al. Exploring the relevance and extent of small airways dysfunction in asthma (ATLANTIS): baseline data from a prospective cohort study. The Lancet Respiratory Medicine. 2019;7(5):402-16.

6. Farah CS, King GG, Brown NJ, Downie SR, Kermode JA, Hardaker KM, et al. The role of the small airways in the clinical expression of asthma in adults. J Allergy Clin Immunol. 2012;129(2):381-7.

7. Gonem S, Natarajan S, Desai D, Corkill S, Singapuri A, Bradding P, et al. Clinical significance of small airway obstruction markers in patients with asthma. Clin Exp Allergy. 2014;44(4):499-507.

8. Bahmer T, Waschki B, Schatz F, Herzmann C, Zabel P, Kirsten A-M et al. Physical activity, airway resistance and small airway dysfunction in severe asthma. Eur Respir J 2017; 49(1).

9. Fuchs O, Bahmer T, Weckmann M, Dittrich A-M, Schaub B, Rösler B, et al. The all age asthma cohort (ALLIANCE) - from early beginnings to chronic disease: a longitudinal cohort study. BMC Pulm Med. 2018;18(1):140.

10. Chung KF, Wenzel SE, Brozek JL, Bush A, Castro M, Sterk PJ, et al. International ERS/ATS guidelines on definition, evaluation and treatment of severe asthma. Eur Respir J. 2014;43(2):343-73.

11. Miller MR, Hankinson J, Brusasco V, Burgos F, Casaburi R, Coates A, et al. Standardisation of spirometry. Eur Respir J. 2005;26(2):319-38.

12. Wanger J, Clausen JL, Coates A, Pedersen OF, Brusasco V, Burgos F, et al. Standardisation of the measurement of lung volumes. Eur Respir J. 2005;26(3):511-22.

13. Oostveen E, MacLeod D, Lorino H, Farré R, Hantos Z, Desager K, et al. The forced oscillation technique in clinical practice: methodology, recommendations and future developments. Eur Respir J. 2003;22(6):1026-41.

14. Chiu H-Y, Hsiao Y-H, Su K-C, Lee Y-C, Ko H-K, Perng D-W. Small airway dysfunction by impulse oscillometry in symptomatic patients with preserved pulmonary function. J Allergy Clin Immunol Pract. 2020;8(1):229-235.e3.

15. Schulz H, Flexeder C, Behr J, Heier M, Holle R, Huber RM, et al. Reference values of impulse oscillometric lung function indices in adults of advanced age. PLoS ONE. 2013;8(5):e63366.

16. Price DB, Rigazio A, Campbell JD, Bleecker ER, Corrigan CJ, Thomas M, et al. Blood eosinophil count and prospective annual asthma disease burden: a UK cohort study. Lancet Respir Med. 2015;3(11):849-58.

17. Dweik RA, Boggs PB, Erzurum SC, Irvin CG, Leigh MW, Lundberg JO, et al. An official ATS clinical practice guideline: interpretation of exhaled nitric oxide levels (FENO) for clinical applications. Am J Respir Crit Care Med. 2011;184(5):602-15.
18. Bel EH, Wenzel SE, Thompson PJ, Prazma CM, Keene ON, Yancey SW, et al. Oral glucocorticoid-sparing effect of mepolizumab in eosinophilic asthma. N Engl J Med. 2014;371(13):1189-97.

19. Schatz M, Kosinski M, Yarlas AS, Hanlon J, Watson ME, Jhingran P. The minimally important difference of the Asthma Control Test. J Allergy Clin Immunol. 2009;124(4):719-23.e1.

20. Farah CS, Badal T, Reed N, Rogers PG, King GG, Thamrin C, et al. Mepolizumab improves small airway function in severe eosinophilic asthma. Respir Med. 2019;148:49-53.

21. Sposato B, Camiciottoli G, Bacci E, Scalese M, Carpagnano GE, Pelaia C, et al. Mepolizumab effectiveness on small airway obstruction, corticosteroid sparing and maintenance therapy step-down in real life. Pulm Pharmacol Ther. 2020;61:101899.

22. Lommatzsch M, Klein M, Stoll P, Virchow JC. Impact of an increase in the inhaled corticosteroid dose on blood eosinophils in asthma. Thorax. 2019;74(4):417-8.

23. Durrington HJ, Gioan-Tavernier GO, Maidstone RJ, Krakowiak K, Loudon ASI, Blaikley JF, et al. Time of day affects eosinophil biomarkers in asthma: implications for diagnosis and treatment. Am J Respir Crit Care Med. 2018;198(12):1578-81.

24. Toledo Pons N, van Fm Boven J, Román-Rodríguez M, Millán A, W.H. Kocks J, B. Soriano J et al. Eosinophil distribution and description in a population cohort of asthmatic patients. In: Monitoring airway disease. European Respiratory Society; 09282019. PA5031.

25. Hamid Q, Song Y, Kotsimbos TC, Minshall E, Bai TR, Hegele RG, et al. Inflammation of small airways in asthma. J Allergy Clin Immunol. 1997;100(1):44-51.

26. Synek M, Beasley R, Frew AJ, Goulding D, Holloway L, Lampe FC, et al. Cellular infiltration of the airways in asthma of varying severity. Am J Respir Crit Care Med. 1996;154(1):224-30.

27. Kelly EA, Esnault S, Liu LY, Evans MD, Johansson MW, Mathur S, et al. Mepolizumab attenuates airway eosinophil numbers, but not their functional phenotype, in asthma. Am J Respir Crit Care Med. 2017;196(11):1385-95.

\section{Publisher's Note}

Springer Nature remains neutral with regard to jurisdictional claims in published maps and institutional affiliations.

Ready to submit your research? Choose BMC and benefit from:

- fast, convenient online submission

- thorough peer review by experienced researchers in your field

- rapid publication on acceptance

- support for research data, including large and complex data types

- gold Open Access which fosters wider collaboration and increased citations

- maximum visibility for your research: over 100M website views per year

At BMC, research is always in progress.

Learn more biomedcentral.com/submissions 